\title{
Video Article \\ Evaluation of Respiratory System Mechanics in Mice using the Forced Oscillation Technique
}

\author{
Toby K. McGovern* ${ }^{1}$, Annette Robichaud ${ }^{2}$, Liah Fereydoonzad ${ }^{2}$, Thomas F. Schuessler ${ }^{2}$, James G. Martin ${ }^{1}$ \\ ${ }^{1}$ Meakins-Christie Laboratories, Department of Medicine, McGill University \\ ${ }^{2}$ SCIREQ Scientific Respiratory Equipment Inc. \\ * These authors contributed equally
}

Correspondence to: Annette Robichaud at Annette.Robichaud@scireq.com

URL: https://www.jove.com/video/50172

DOI: doi:10.3791/50172

Keywords: Medicine, Issue 75, Biomedical Engineering, Anatomy, Physiology, Biophysics, Pathology, lung diseases, asthma, respiratory function tests, respiratory system, forced oscillation technique, respiratory system mechanics, airway hyperresponsiveness, flexiVent, lung physiology, lung, oxidative stress, ventilator, cannula, mice, animal model, clinical techniques

Date Published: 5/15/2013

Citation: McGovern, T.K., Robichaud, A., Fereydoonzad, L., Schuessler, T.F., Martin, J.G. Evaluation of Respiratory System Mechanics in Mice using the Forced Oscillation Technique. J. Vis. Exp. (75), e50172, doi:10.3791/50172 (2013).

\section{Abstract}

The forced oscillation technique (FOT) is a powerful, integrative and translational tool permitting the experimental assessment of lung function in mice in a comprehensive, detailed, precise and reproducible manner. It provides measurements of respiratory system mechanics through the analysis of pressure and volume signals acquired in reaction to predefined, small amplitude, oscillatory airflow waveforms, which are typically applied at the subject's airway opening. The present protocol details the steps required to adequately execute forced oscillation measurements in mice using a computer-controlled piston ventilator (flexiVent; SCIREQ Inc, Montreal, Qc, Canada). The description is divided into four parts: preparatory steps, mechanical ventilation, lung function measurements, and data analysis. It also includes details of how to assess airway responsiveness to inhaled methacholine in anesthetized mice, a common application of this technique which also extends to other outcomes and various lung pathologies. Measurements obtained in naïve mice as well as from an oxidative-stress driven model of airway damage are presented to illustrate how this tool can contribute to a better characterization and understanding of studied physiological changes or disease models as well as to applications in new research areas.

\section{Video Link}

The video component of this article can be found at https://www.jove.com/video/50172/

\section{Introduction}

Adequate characterization of the mechanical properties of the lungs in small animals has become essential since the burgeoning of murine models in respiratory science. When performed using the forced oscillation technique (FOT), a technique also used in human subjects, these measurements provide a powerful, integrative and translational approach to study meaningful physiological changes. FOT measurements are typically obtained by analyzing pressure and volume signals acquired in reaction to a predefined, small amplitude, oscillatory airflow waveform (also referred to as perturbation or input signal) applied at the subject's airway opening ${ }^{1}$. In its simplest form, a FOT perturbation would be a single sinusoidal waveform at a well-defined frequency. More complex perturbations typically consist of a superposition of a selection of specific (mutually prime) frequency waveforms covering a broad spectrum. The decomposition of the multi-frequency input and output signals into their constituents using the Fourier transform allows the calculation of respiratory system input impedance (Zrs), i.e. the transfer function between the input and output signals, at every frequency included in the perturbation ${ }^{2}$. Therefore, FOT permits the simultaneous assessment of respiratory mechanics over a range of frequencies in a single maneuver ${ }^{2}$. Fitting advanced mathematical models (e.g. the Constant Phase $\mathrm{Model}^{3}$ ) to the impedance data then permit a partitioning of the response into airway (central and peripheral) and parenchymal lung tissue dependent parameters ${ }^{1,3}$. Because many factors influencing the physiological response (e.g. breathing frequency, tidal volume, lung volume, upper airways, spontaneous breathing efforts, timing of measurements) are controlled and standardized by the measurement system and experimental procedures, ${ }^{1}$ the technique is capable of generating precise and reproducible measurements provided that it is performed correctly. The objective of this article is to provide a detailed, chronological description of the procedure needed in order to execute such measurements in mice. The protocol consists of four parts: preparatory steps (reagents, equipment and subjects), mechanical ventilation, lung function measurements, and data analysis. Examples of representative results of respiratory system mechanics generated using a computer-controlled piston ventilator (flexiVent, SCIREQ Inc, Montreal, Qc, Canada) are provided. These were obtained from naïve mice as well as from an oxidativestress driven model of airway damage characterized by airway inflammation, epithelial cell damage and increased airway responsiveness to inhaled aerosolized methacholine ${ }^{4}$. While this protocol is often used to assess airway responsiveness to inhaled methacholine, it extends to other outcomes and various pathologies including asthma, chronic obstructive pulmonary disease (COPD), emphysema, lung fibrosis, lung injury as well as to transgenic mouse models of pathologies similar to human disease. Research findings using this tool can contribute to a better characterization and understanding of physiological changes or disease models as well as to expansion into new research areas. 


\section{Protocol}

The procedures described below were approved by McGill University Institutional Animal Care Committee in accordance with the guidelines of the Canadian Council on Animal Care (CCAC).

\section{Preparatory Steps}

1. Solutions:

1. Methacholine: Prepare a stock solution at $50 \mathrm{mg} / \mathrm{ml}$ and make serial dilutions (1:1) based on the concentrations to be tested ${ }^{5}$. Allow the solutions to reach room temperature before nebulizing ${ }^{5}$.

2. Anesthetic agents: Different regimens have been reported in the literature in various strains of mice (Table 1). Note: Regimen 1 was used under the present protocol.

2. Equipment: The present protocol applies to either of the two flexiVent generations supported by flexiWare 7 software. The software functions are grouped under three modules: Study Definition \& Planning, Experimentation Session and Review \& Reporting.

1. Turn on the system (flexiVent FX only) and/or start the software.

2. At the first experimentation session or any time before it, open the Study Definition \& Planning module to predefine the study structure.

3. Click on the Create a new study button and follow the wizard to create a study, outline the protocol and define the experimental groups and subjects to be studied.

4. Initiate an experimentation session by opening the Experimentation Session module and following the start-up sequence for study and template selection.

5. Assign a subject to the measurement site and confirm its weight.

6. Proceed with the calibration of the system by following the steps described in the operating software. You will be prompted at one point to attach the cannula to be used (step 1.3.3) to the Y-tubing for calibration.

7. Critical step. Repeat step 1.2.6 if the calibration values obtained are outside the acceptable range. (Refer to the flexiVent FX or flexiWare 7 user manual for the module specific acceptable ranges of calibration values).

8. Cancel prompts to start ventilation and data recording unless ready to start the experiment. These can be initiated at a later point.

3. Subjects:

1. Anesthetize the subject using appropriate doses of anesthetic agents (Table 1)

2. Verify that the subject has reached a surgical level of anesthesia. The subject should show no reaction to a toe pinch and its breathing should be regular and not labored.

3. Perform a tracheotomy and cannulate the trachea.

1. Place the animal on its back and provide a source of heat (e.g. temperature controlled heating blanket or a lamp with a 60 watt bulb situated approximately $45 \mathrm{~cm}$ from the mouse to avoid excessive heating).

2. Clean the throat area with alcohol and expose the trachea by making a skin incision and gently separating the submaxillary gland and the muscle layer covering it.

3. Gently lift the trachea using a pair of micro-forceps and pass suture underneath it.

4. Cut between two rings of cartilage nearest the larynx to make a small incision in the trachea without sectioning it.

5. Insert the previously calibrated cannula into the incision and advance it gently inside the trachea the length of approximately 5 rings. Note: The present experiments were conducted using a $1.2 \mathrm{~cm}$ long metal 18 gauge cannula.

6. Critical step. Secure the cannula in place using the suture. The attachment should form an airtight seal around the cannula.

\section{Mechanical Ventilation}

1. Bring the animal close to the ventilator.

2. Start mechanical ventilation by selecting a predefined or a customized ventilation profile in the ventilation docker.

3. Connect the animal to the ventilator via the Y-tubing.

4. Critical step. Align the animal to the ventilator and ensure that the tracheal cannula is at the same level as the ventilator to avoid a possible cannula occlusion or tracheal twist.

5. Critical Step. Execute a Deep Inflation perturbation by double-clicking on the perturbation name to verify the cannula insertion and attachment. In absence of a leak, the system should be able to hold a pressure of $30 \mathrm{cmH}_{2} \mathrm{O}$ over a 3 second period without excessive volume displacement (Figure 1). The recorded volume and pressure traces should also be smooth with no signs of offset or deformation as these could indicate a cannula obstruction or misplacement.

6. If needed, connect vital sign transducers for heart rate and body temperature monitoring. Data recording can be initiated either manually or automatically via a script.

\section{Lung Function Measurements}

Measurements or commands (e.g. nebulizer activation, event markers) can be automated using predefined or customized scripts for a highly controlled and repeatable experimental process (Figure 2). Six families of perturbations giving rise to a number of parameters can be used to describe the subject respiratory system mechanics at baseline and following a given challenge (Table 2).

1. Critical step. When ready to start taking measurements, run a Deep Inflation to recruit closed lung areas and standardize lung volume history. 
2. Critical step. Verify the absence of spontaneous inspiratory efforts by running a test measurement (e.g. PVs-P or PVs-V). Observe the pressure signal traces in the Selected Dataset view. With stepwise PV curves, pressure plateaus should be well defined with no downwards deflections. A downward swing in pressure would indicate an inspiratory effort from the animal (Figure 3).

3. Initiate the selected script by double-clicking on its title. Scripts used in the present study generally included for measurements:

- A sequence of baseline measurements in triplicate.

- Activation of the nebulizer for assessment of airway responsiveness to inhaled methacholine. Note: When prompted by the system, load approximately $100 \mu \mathrm{l}$ of saline or of a solution of methacholine into the nebulizer. Nebulization will start and stop automatically.

- A sequence of closely spaced measurements (every 10-15 sec) for a period of approximately 3 min following the activation of the nebulizer.

- A prompt to perform another challenge and repeat a sequence of measurements. Note: Drying the inside the nebulizer mount with a swab in between challenges can help prevent droplets or condensation from building-up in the inspiratory line.

4. At the end of the experiment, stop ventilation and detach the subject.

5. Switch to the next subject in the operating software and confirm its weight.

6. Critical step. Rinse and dry nebulizer, adaptor, Y-tubing, and cannula between subjects.

7. Repeat steps 1.2 .6 to 3.6 .

8. At the end of the day, close the experimental session. Remember to rinse and dry nebulizer, adaptor, Y-tubing, and cannula and to clean the system expiratory valve before leaving the laboratory by following the manufacturer's instructions.

\section{Data Analysis}

The software automatically calculates and displays parameters associated with a perturbation. It also provides a coefficient of determination (COD) which reflects the fit of the mathematical model to the data. Each dataset with an insufficient COD is labelled as excluded by the software. Review of experimental sessions, data re-analysis and creation of export scenarios are done in the Review \& Reporting module of the software.

1. Open the Review \& Reporting module and create an export scenario, taking care to only include datasets having a sufficient COD.

2. Export as needed parameters, pressure- or flow-volume curve, raw dataset signals or subject information to a spreadsheet application (see Table 3).

3. Average baseline measurements for each parameter and plot all measurements as a function of time (see Figure 4). You may then choose to calculate the area under the curve, analyze the general profile of the curves or perform a statistical analysis.

4. To express airway responsiveness results as a function of the concentration of methacholine, determine for each subject, parameter and experimental condition either a specific point (e.g. peak) or a specific time after each methacholine challenge. Calculate group averages and report or plot results for each experimental condition (Table 4, Figure 5).

5. You may also consider calculating the concentration producing a doubling of a given parameter baseline value $\left(\mathrm{PC}_{200}\right.$; Figure $\left.5 \mathbf{C}\right)$, applying a normalization (e.g. \% baseline) or performing a statistical analysis.

\section{Representative Results}

Respiratory system mechanics measurements. Table 4 shows typical results from naïve A/J mice obtained at baseline and following methacholine-induced bronchoconstriction $(12.5 \mathrm{mg} / \mathrm{ml})$ using either of the two flexiVent generations supported by flexiWare 7 software. Mechanics of the respiratory system, i.e. under closed chest conditions, were assessed by alternating perturbations of the single and broadband frequency forced oscillation families in a closely spaced manner (SnapShot-150, Quick Prime-3, respectively). Since ventilation is paused during measurements, the Quick Prime-3, which covers a similar frequency range as the Prime-8 but has a shorter duration ( 3 vs 8 sec), was selected in order to shorten the apneic period, minimize the effect of the perturbation on blood gases and provide a better resolution of the response. Parameters associated with each perturbation were calculated automatically by the operating software. Results illustrate that the two generations of the flexiVent system produced equivalent measurements of respiratory mechanics.

Site of lung response. Distinguishing the site of lung response allows the investigator to further pinpoint affected regions as well as to identify potential points of pharmacological intervention ${ }^{6}$. For example, naïve $\mathrm{A} / \mathrm{J}$ mice show an increase of baseline resistance when the end expiratory pressure against which measurements are made is increased from 3 to $9 \mathrm{cmH}_{2} \mathrm{O}$ (Figure $6 \mathrm{~A}$, SnapShot-150). In the present example, the use of broadband FOT measurements (Quick Prime-3) provided details to clarify the basis for the change in resistance: The change in end expiratory pressure resulted in a decrease in the airway resistance $\left(R_{N}\right)$ consistent with the bronchodilating effects of a higher lung volume and the larger inflation pressure (Figure 6D) and an increase in tissue damping (G; Figure 6E), a parameter closely related to tissue resistance that reflects tissue viscoelasticity and possibly the resistance of the small airways ${ }^{7}$. The latter is known to increase with increasing lung volume.

Airway hyperresponsiveness. Following chlorine gas exposure, airway responsiveness to inhaled methacholine increases compared to air exposure in Balb/c mice as a result of airway damage ${ }^{4}$ (Figure 2). Chlorine is known to induce oxidative stress, leading to destruction of structural cells in the airways, in particular epithelial cells, and inducing recruitment of inflammatory cells. As represented in Figure 5, changes in all parameters describing respiratory system mechanics can be seen in response to increasing methacholine challenges. In comparison to air-exposed mice, mice exposed to chlorine gas displayed greater maximal responses at all FOT parameters (Figure 5A, 5B, 5D-5F) as well as a statistically significant leftward shift of the concentration-response curve exemplified by a reduction of the concentration of methacholine required to cause a doubling in resistance and elastance ( $\mathrm{PC}_{200}$; Figure $\left.\mathbf{5 C}\right)$. Those results illustrate, respectively, airway hyperresponsiveness and hypersensitivity to inhaled methacholine following exposure to chlorine gas.

Other measurements. In addition to FOT, the flexiVent system can also be used to collect other types of lung function ${ }^{8-10}$ or cardiovascular $^{11}$ measurements. Figure 7 displays a representative stepwise, pressure-driven pressure-volume curve in naïve $\mathrm{A} / \mathrm{J}$ mice under baseline conditions. The upper portion of the deflation limb of the curve is fit to the Salazar-Knowles equation ${ }^{12}$ and parameters are automatically calculated by the software. 


\begin{tabular}{|c|l|l|l|l|}
\hline Regimen & $\begin{array}{l}\text { Pre-anesthetic medication } \\
\text { (mg/kg, ip) }\end{array}$ & $\begin{array}{l}\text { Anesthetic Agents } \\
\text { (mg/kg, ip) }\end{array}$ & Support Treatment & References \\
\hline 1 & $\begin{array}{l}\text { Xylazine (8-12) } \\
\text { Ketamine (130)/Diazepam (7) }\end{array}$ & Sodium Pentobarbital (30-70) & $\begin{array}{l}\text { Pancuronium } \\
(0.8-1.2 \mathrm{mg} / \mathrm{kg}, \text { ip) }\end{array}$ & $4,19-21$ \\
\hline 2 & & Sodium Pentobarbital (90) & $\begin{array}{l} \pm \text { Pancuronium } \\
(0.8 \text { ug/kg, ip) }\end{array}$ & 22,23 \\
\hline 3 & & Xylazine (2-13)/ Ketamine (40-65) & \pm hyperventilation & $6,24,25$ \\
\hline 4 & & Diazepam (17.5)/ Ketamine (450) & & 26 \\
\hline 5 & & Avertin (240) & $\begin{array}{l}\text { Pancuronium } \\
\text { (0.03 mg/kg, iv) }\end{array}$ & 27 \\
\hline 6 & & Isoflurane (3\%) & $\begin{array}{l}\text { Pancuronium } \\
(1 \text { ug, ip) }\end{array}$ & 28 \\
\hline
\end{tabular}

Table 1. Examples of anesthetic regimens used in mice. Click here to view larger table.

\begin{tabular}{|c|c|c|}
\hline $\begin{array}{l}\text { Perturbation } \\
\text { Families }\end{array}$ & $\begin{array}{l}\text { Perturbation } \\
\text { Names }\end{array}$ & Typical Parameters \\
\hline $\begin{array}{l}\text { Recruitment } \\
\text { maneuver }\end{array}$ & Deep Inflation & - IC: inspiratory capacity \\
\hline $\begin{array}{l}\text { Single } \\
\text { frequency } \\
\text { forced } \\
\text { oscillation }\end{array}$ & SnapShot-150 & $\begin{array}{l}\text { Single Compartment Model parameters: } \\
\text { - R: resistance of respiratory system } \\
\text { - E: elastance of respiratory system } \\
\text { - C: Dynamic compliance }\end{array}$ \\
\hline $\begin{array}{l}\text { Broadband } \\
\text { frequency } \\
\text { forced } \\
\text { oscillation }\end{array}$ & $\begin{array}{l}\text { Quick Prime-3 } \\
\text { Prime-8 }\end{array}$ & $\begin{array}{l}\text { Constant Phase Model parameters: } \\
\text { - } \mathrm{R}_{\mathrm{N}} \text { : Newtonian resistance (resistance of } \\
\text { the airways) } \\
\text { - } \mathrm{G}: \text { Tissue damping (related to tissue } \\
\text { resistance) } \\
\text { - } \mathrm{H} \text { : Tissue elastance } \\
\text { - } \mathrm{\eta} \text { : ratio of } \mathrm{G} / \mathrm{H}\end{array}$ \\
\hline $\begin{array}{l}\text { Pressure - } \\
\text { volume } \\
\text { curve }\end{array}$ & $\begin{array}{l}\text { PVs-V } \\
\text { PVr-V } \\
\text { PVs-P } \\
\text { PVr-P }\end{array}$ & $\begin{array}{l}\text { - Pressure-volume curve } \\
\text { - } \mathrm{C}_{\text {st: }} \text { Quasi-static compliance } \\
\text { - Area: Area between the inspiratory and } \\
\text { expiratory limb of the pressure-volume } \\
\text { curve } \\
\text { - Salazar-Knowles parameter A: estimate of } \\
\text { inspiratory capacity } \\
\text { - Salazar-Knowles parameter K: curvature } \\
\text { of the upper portion of expiratory limb of } \\
\text { P-V curve. }\end{array}$ \\
\hline \begin{tabular}{l|} 
Negative \\
pressure - \\
driven forced \\
expiration
\end{tabular} & NPFE* & 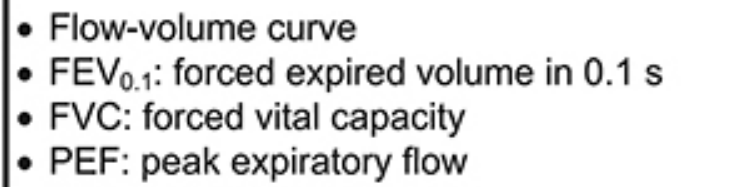 \\
\hline $\begin{array}{l}\text { Gated image } \\
\text { acquisition }\end{array}$ & & \\
\hline
\end{tabular}

Table 2. Perturbations used for lung function measurements in mice. *Extension required to the system. The subject also needs to be in a closed plethysmograph chamber during measurements. Click here to view larger table. 


\begin{tabular}{|l|l|c|c|c|c|c|c|c|c|}
\hline & & \multicolumn{3}{|c|}{ Single-Compartment Model } & \multicolumn{4}{|c|}{ Constant-Phase Model } \\
\hline Subject & Perturbation & $\mathbf{R}_{\mathrm{rs}}$ & $\mathbf{C}_{\mathrm{rs}}$ & $\mathbf{E}_{\mathrm{rs}}$ & $\mathbf{C O D}$ & $\mathbf{R}_{\mathbf{N}}$ & $\mathbf{G}$ & $\mathbf{H}$ & $\mathbf{C O D}_{\mathrm{cp}}$ \\
\hline Mouse 2 & SnapShot-150 v7.0 & 0.5978 & 0.0423 & 23.6534 & 0.9995 & & & & \\
\hline Mouse 2 & Quick Prime-3 v7.0 & & & & & 0.3381 & 4.0771 & 21.2276 & 0.9821 \\
\hline Mouse 2 & SnapShot-150 v7.0 & 0.5935 & 0.0415 & 24.0712 & 0.9993 & & & & \\
\hline Mouse 2 & Quick Prime-3 v7.0 & & & & & 0.3286 & 4.1327 & 21.6388 & 0.9857 \\
\hline Mouse 2 & SnapShot-150 v7.0 & 0.6005 & 0.0411 & 24.3310 & 0.9987 & & & & \\
\hline Mouse 2 & Quick Prime-3 v7.0 & & & & & 0.3334 & 4.0493 & 21.5056 & 0.9824 \\
\hline
\end{tabular}

Table 3. Example of exported parameters from the single and broadband frequency forced oscillation perturbation families. Click here to view larger table.

\begin{tabular}{|c|c|c|c|c|c|c|c|}
\hline \multirow[b]{2}{*}{ Perturbation } & \multirow[b]{2}{*}{$\begin{array}{l}\text { Parameters } \\
\text { (units) }\end{array}$} & \multirow[b]{2}{*}{$\begin{array}{l}\text { Conditions } \\
\text { Studied }\end{array}$} & \multicolumn{2}{|c|}{$\begin{array}{c}\text { flexiVent } \\
\left(1^{\text {st }} \text { generation }\right)\end{array}$} & \multicolumn{2}{|c|}{ flexiVent FX } & \multirow[b]{2}{*}{$p<0.05^{\star}$} \\
\hline & & & Mean & SD & Mean & SD & \\
\hline \multirow{4}{*}{ SnapShot-150 } & \multirow{2}{*}{$\begin{array}{c}\mathrm{R} \\
\text { (cm H} \mathrm{H}_{2} \mathrm{O} . \mathrm{s} / \mathrm{ml} \text { ) }\end{array}$} & Baseline & 0.59 & 0.03 & 0.57 & 0.06 & ns \\
\hline & & Mch & 3.70 & 1.92 & 2.79 & 0.76 & $\mathrm{~ns}$ \\
\hline & \multirow{2}{*}{$\begin{array}{c}\mathrm{E} \\
\left(\mathrm{cm} \mathrm{H} \mathrm{H}_{2} \mathrm{O} / \mathrm{ml}\right)\end{array}$} & Baseline & 23.14 & 2.22 & 23.27 & 2.92 & $\overline{\mathrm{ns}}$ \\
\hline & & Mch & 91.09 & 62.30 & 71.15 & 20.46 & $\overline{\mathrm{ns}}$ \\
\hline \multirow{6}{*}{ Quick Prime-3 } & \multirow{2}{*}{$\begin{array}{c}\mathrm{R}_{\mathrm{N}} \\
\left(\mathrm{cm} \mathrm{H} \mathrm{H}_{2} \mathrm{O} . \mathrm{s} / \mathrm{ml}\right)\end{array}$} & Baseline & 0.32 & 0.03 & 0.29 & 0.02 & $\mathrm{~ns}$ \\
\hline & & Mch & 1.39 & 0.66 & 0.93 & 0.14 & $\mathrm{~ns}$ \\
\hline & \multirow{2}{*}{$\begin{array}{c}\mathrm{G} \\
\left(\mathrm{cm} \mathrm{H} \mathrm{H}_{2} \mathrm{O} / \mathrm{ml}\right)\end{array}$} & Baseline & 4.12 & 0.29 & 4.18 & 0.43 & $\mathrm{~ns}$ \\
\hline & & Mch & 18.40 & 8.25 & 15.88 & 4.24 & $\mathrm{~ns}$ \\
\hline & \multirow{2}{*}{$\begin{array}{c}\mathrm{H} \\
\left.\text { (cm H} \mathrm{H}_{2} \mathrm{O} / \mathrm{ml}\right)\end{array}$} & Baseline & 21.40 & 2.05 & 20.5 & 2.5 & $\mathrm{~ns}$ \\
\hline & & Mch & 46.02 & 24.58 & 38.4 & 9.2 & $\mathrm{~ns}$ \\
\hline
\end{tabular}

Table 4. System Comparison. Comparison of lung mechanics parameters collected using the two generations of the flexiVent system operated by flexiWare 7 software. Results were generated in naïve A/J mice ( $n=5 / g r o u p)$ at baseline and following methacholine-induced bronchoconstriction (Mch $12.5 \mathrm{mg} / \mathrm{ml}$ ). *Groups were compared using a two-way ANOVA for repeated measurements and the log ${ }_{10}$ of individual responses for homogeneity of variances (GraphPad Prism, version 5.03; GraphPad Software, San Diego, USA). 


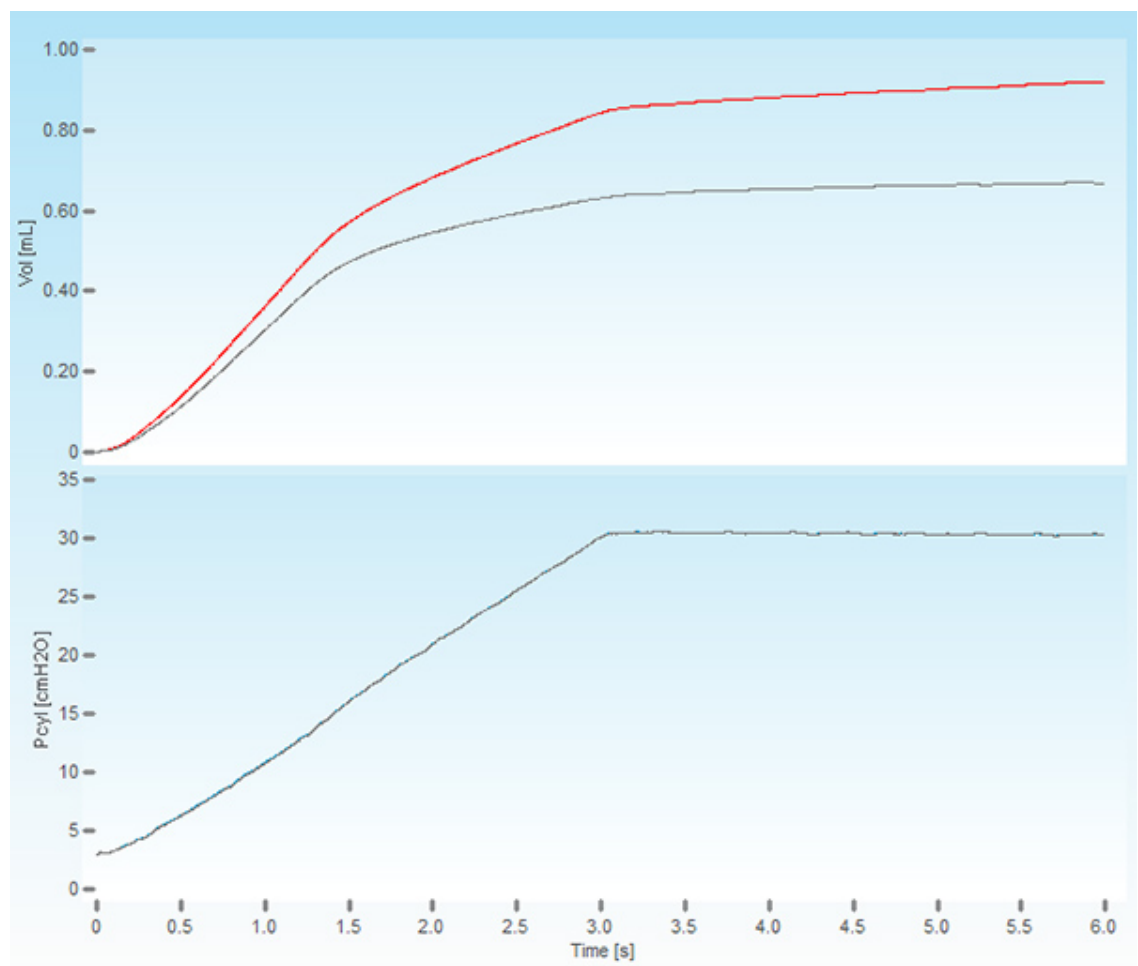

Figure 1. Screenshot of a deep lung inflation. The upper panel shows the volume displaced by the piston of the ventilator (red trace) and the volume delivered to the subject (grey trace). The lower panel displays the cylinder pressure increasing to a set pressure of $30 \mathrm{cmH}_{2} \mathrm{O}$ over a period of 3 seconds and held constant for the same time period.

\section{StartScript}

//start default ventilation

00:00 StartVentilation pattern='Mouse Default CMV'

//perform baseline measurements

00:00 loop count $=3$

00:28 Perturbation name='Deep Inflation v7.0'

$00: 12$ Perturbation name='Snapshot-150 v7.0'

00:06 Perturbation name='Quick Prime-3 v7.0'

00:08 Perturbation name='PVs-P v7.0'

00:00 endloop

// useful shortcuts: CTRL-J for command templates

/I

CTRL-SPACE for completion

\section{EndScript}

Figure 2. Example of a typical script used to assess respiratory system mechanics at baseline. 
jove Journal of Visualized Experiments

www.jove.com
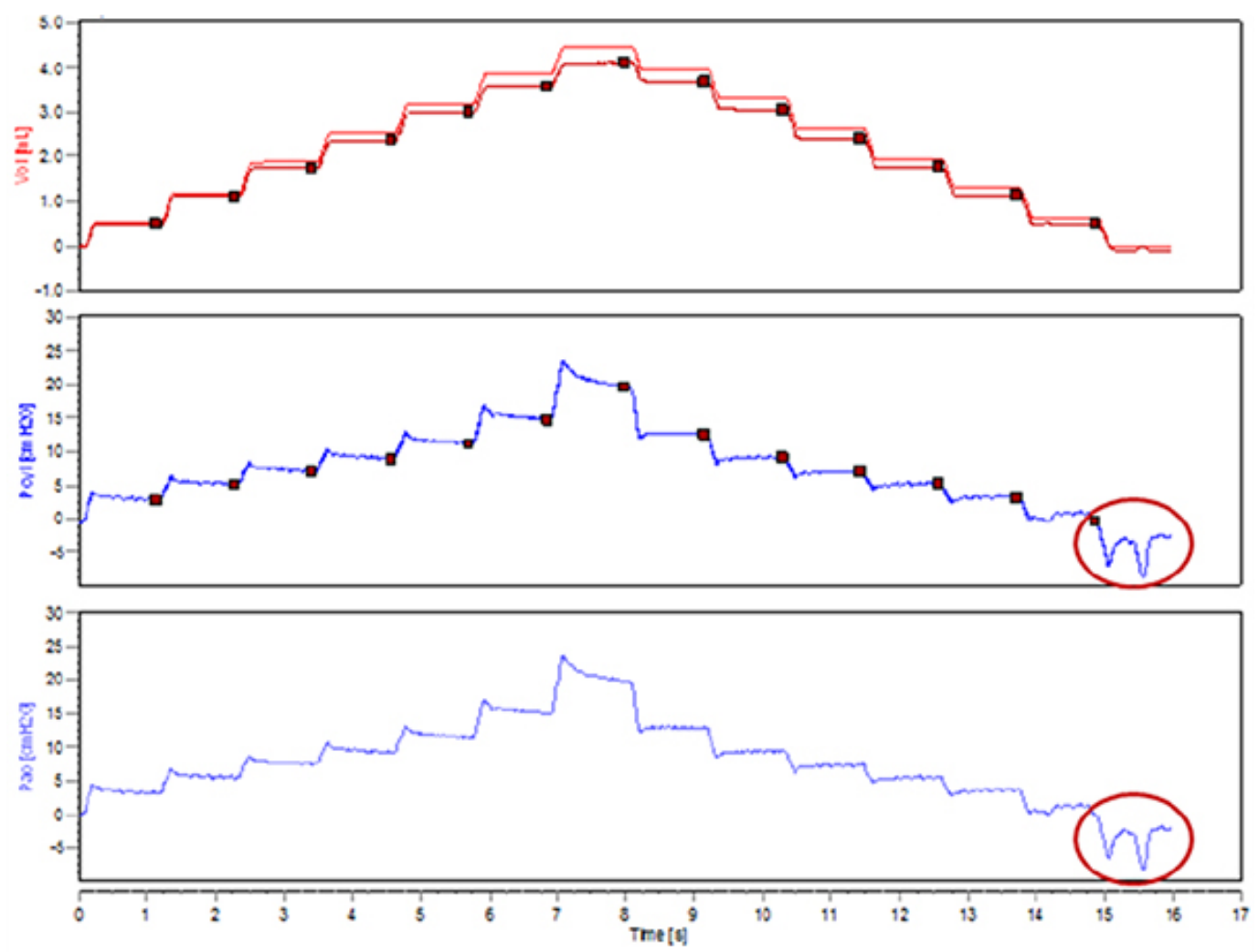

Figure 3. Spontaneous inspiratory efforts during the execution of a stepwise pressure-volume curve.

Copyright @ 2013 Journal of Visualized Experiments and SCIREQ Scientific Respiratory

May $2013 \mid 75$ | e50172| Page 7 of 12

Equipment, Inc. 

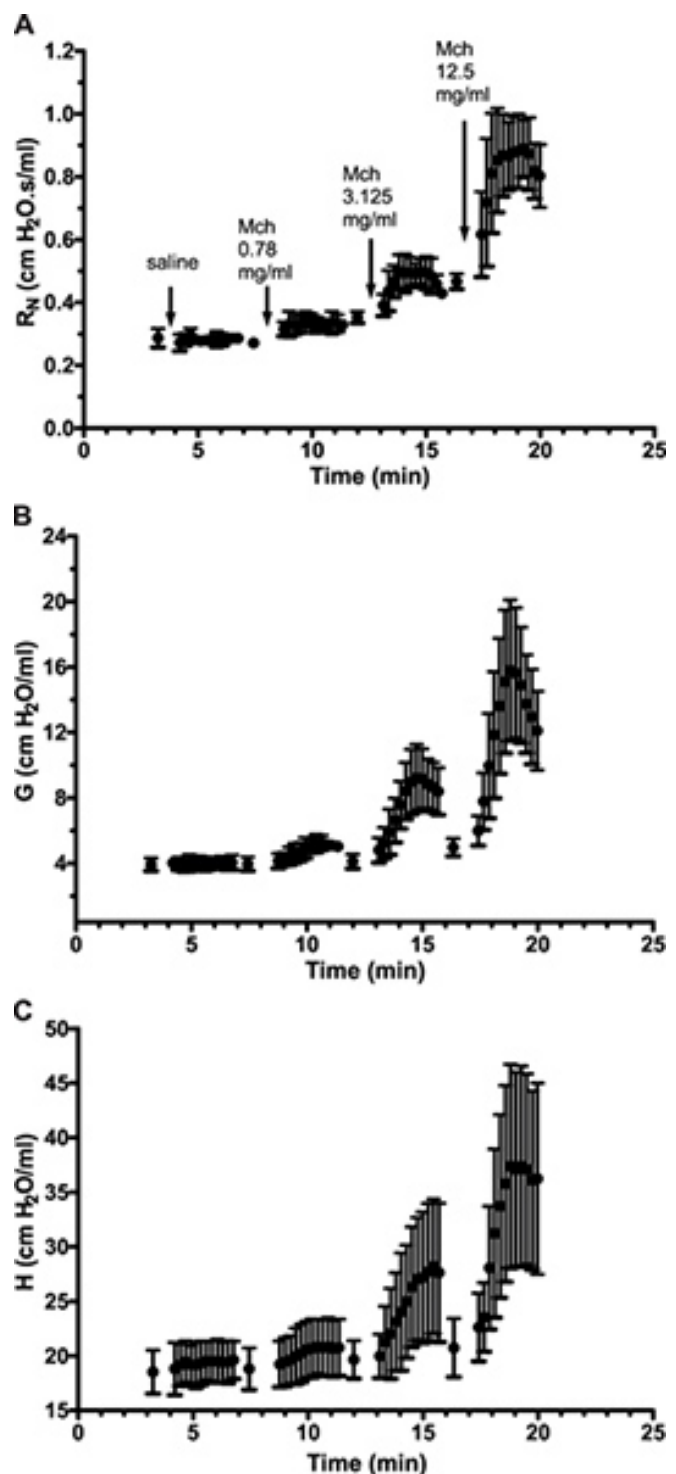

Figure 4. Time-course response following increasing inhaled methacholine challenges. Results are expressed as the mean $( \pm$ standard deviation) of a group of 5 naïve spontaneously hyperresponsive $\mathrm{A} / \mathrm{J}$ mice. Click here to view larger figure. 
Single frequency FOT $(2.5 \mathrm{~Hz})$
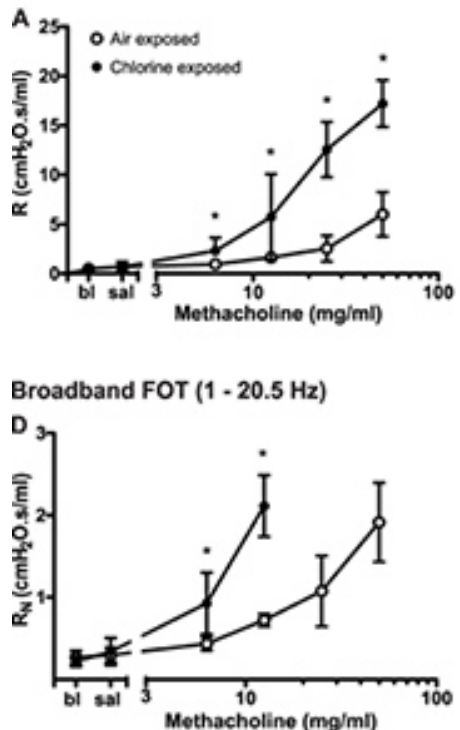
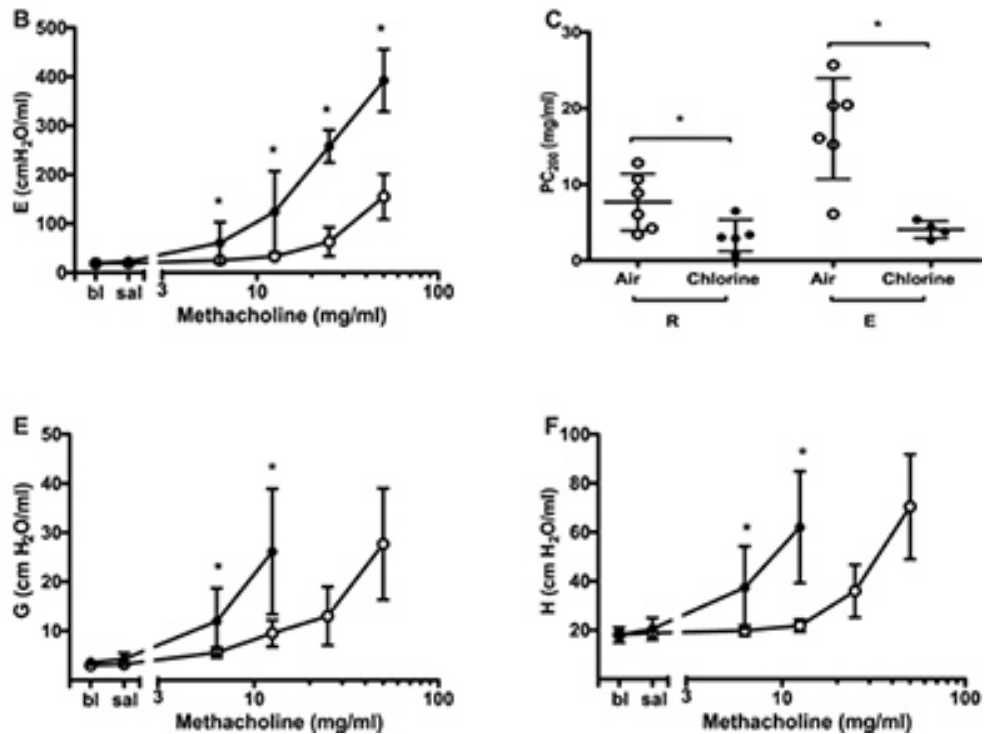

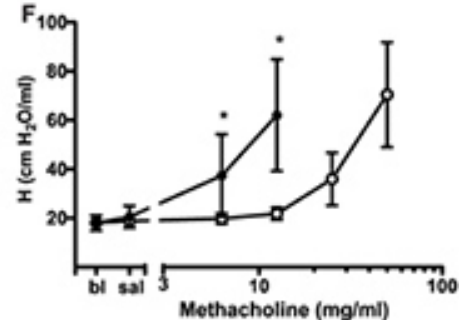

Figure 5. Changes in respiratory system mechanics following increasing methacholine challenges in chlorine- and air-exposed Balb/ c mice. Peak value was identified for each parameter in every subject and experimental condition. Group averages were then calculated (mean \pm standard deviation; $\mathrm{n}=4-6$ ). Differences between groups were assessed by analysis of variance using the log ${ }_{10}$ of individual responses for homogeneity of variances. The concentration of methacholine producing a doubling of baseline $\left(\mathrm{PC}_{200}\right)$ was obtained by fitting a second order polynomial to individual dose-response curves and interpolation of the fitted curve. Data points are missing in $\mathbf{D}, \mathbf{E}$ and $\mathbf{F}$ in the chlorineexposed mice at the two highest methacholine concentrations due to insufficiently high coefficients of determination reflecting a poor fit of the mathematical model to the data. Click here to view larger figure.

Single frequency FOT $(2.5 \mathrm{~Hz})$

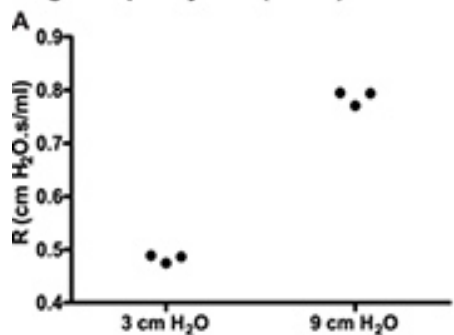

Broadband FOT $(1-20.5 \mathrm{~Hz})$

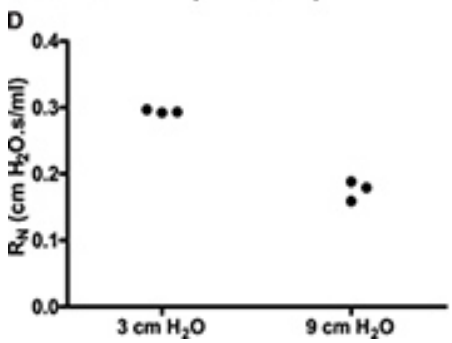

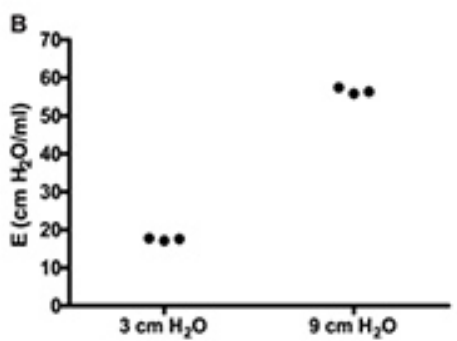
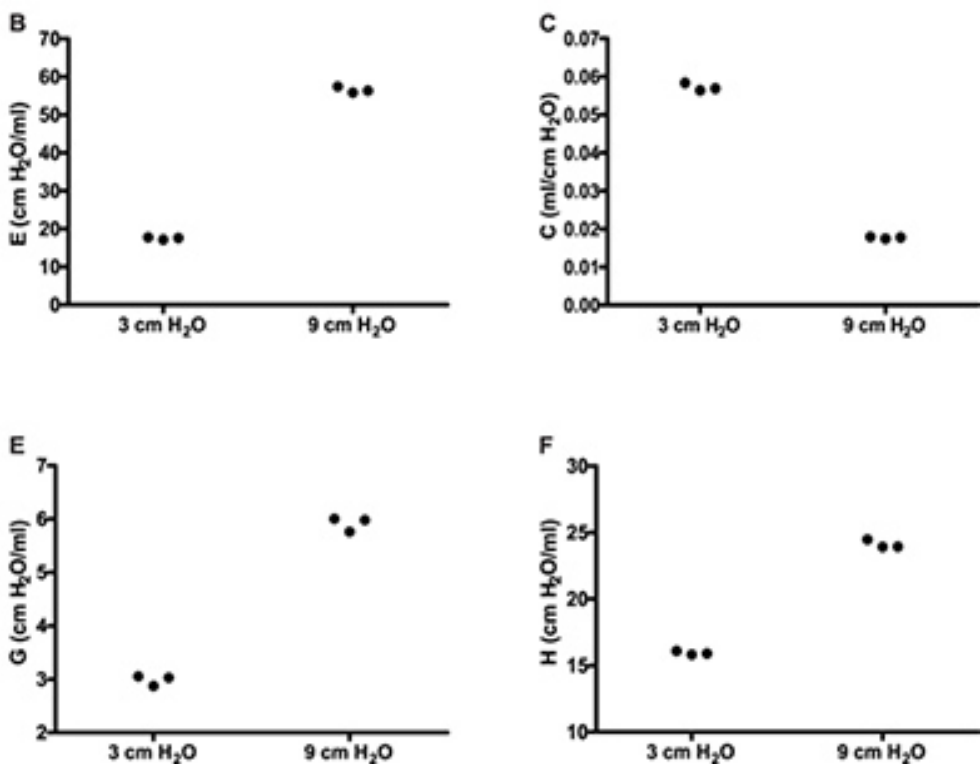

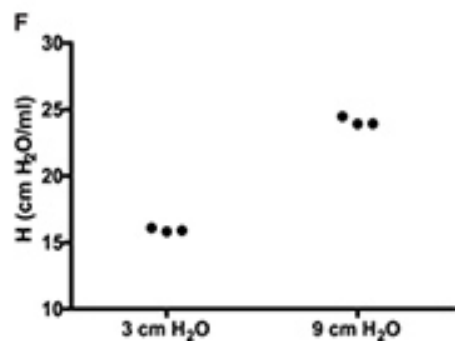

Figure 6. Partitioning of the respiratory response into airway and lung tissue mechanics. Experimental trace from a naïve $\mathrm{A} / \mathrm{J}$ mice illustrating single $(2.5 \mathrm{~Hz})$ and broadband $(1-20.5 \mathrm{~Hz})$ frequency forced oscillation measurements of respiratory mechanics in triplicate at two different end expiratory pressures $\left(3 \& 9 \mathrm{cmH}_{2} \mathrm{O}\right)$. Click here to view larger figure. 


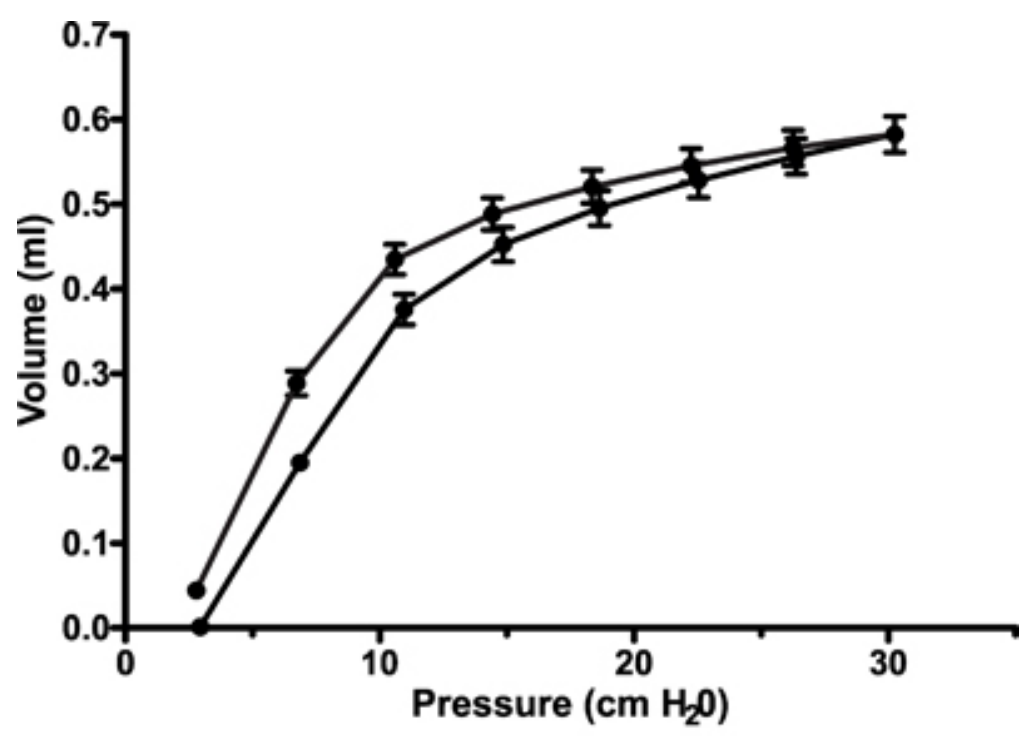

\begin{tabular}{|l|c|c|c|c|}
\hline Parameters & Mean & $\begin{array}{c}\text { Standard } \\
\text { Deviation }\end{array}$ & $\begin{array}{c}\text { Coefficient of } \\
\text { Variation (\%) }\end{array}$ & $\mathbf{n}$ \\
\hline $\mathrm{A}(\mathrm{ml})$ & 0.564 & 0.041 & 7.20 & 6 \\
\hline $\mathrm{K}\left(/ \mathrm{cmH}_{2} \mathrm{O}\right)$ & 0.169 & 0.012 & 7.00 & 6 \\
\hline $\mathrm{C}_{\text {st }}\left(\mathrm{ml} / \mathrm{cmH}_{2} \mathrm{O}\right)$ & 0.06 & 0.007 & 11.20 & 6 \\
\hline Area $\left(\mathrm{ml} . \mathrm{cmH}_{2} \mathrm{O}\right)$ & 1.174 & 0.094 & 8.00 & 6 \\
\hline
\end{tabular}

Figure 7. Pressure-volume curve in naïve A/J mice under baseline conditions. Pressure-volume curves were generated using a stepwise pressure-driven perturbation (PVs-P) to ensure that each mouse lungs were inflated to the same pressure, independently of their condition. Salazar-Knowles equation parameters extracted from individual pressure-volume curves were also averaged and reported in a table format. Results are expressed as the mean \pm standard deviation $(n=6)$.

\section{Discussion}

The continued study of airway dysfunction as it relates to asthma and other lung disorders remains paramount to the understanding of underlying mechanisms of disease and the development of treatment options. The use of mice to model airway disease has been essential in gaining understanding into these disease mechanisms. When considering evaluating airway dysfunction in a subject as small as a mouse, having reliable and accurate tools by which to measure lung function is critical. Furthermore, having tools capable of providing insights on the location of airway dysfunction or therapeutic effect is invaluable. The FOT technique combines all these attributes and provides a powerful, integrative and translational approach to evaluate physiological changes.

In order to succeed with this type of measurement in mice, special attention should be given to a few steps, namely the calibration of the system, the resistance of the endotracheal cannula, the type of nebulizer (as well as its operating settings) the positioning of the animal and the standardization of lung volume history. In addition, it is imperative in order to obtain valid datasets that the subject's respiratory system remains passive during measurements. This can be achieved by the administration of a muscle paralyzing agent, working at a deep plane of anesthesia or by hyperventilating the subject to induce apnea (see Table 1). Investigators can start by mastering the system and its operating software, if desired, with test loads, while acquiring the necessary skills for measurements in mice. It would then be logical to generate reproducible results in naïve animals before moving to disease models or treated mice. Since an important proportion of disease models in respiratory research involve exposing animals to agents such as allergens, toxins, pollutants, cigarette smoke or gases, variability in the results obtained with the measurement technique described in this article could therefore be influenced by the exposure procedure used. Standardization of key experimental processes (e.g. using computer-controlled exposure and measurement systems ${ }^{6,13,14}$ ) could potentially have a significant impact in reducing variability.

Examples presented in this article represent a selection of typical results from naïve and chlorine-exposed mice experiments while highlighting the strengths as well as the limitations of the technique. As can be seen for example in Figure 6, the technique is capable of generating reproducible lung function measurements. While similar baseline resistance values were reported between mouse strains, differences in elastance were however observed ${ }^{15}$. Substantial changes are also to be expected between infant and adult mice ${ }^{16}$. As for other in vivo physiological assessment, high precision results, such as those generated by the FOT, come with a concession as to the natural state of the subjects. This principle, which is referred to as the phenotyping uncertainty principle ${ }^{1}$, applies to the present protocol in the sense that measurements need to be made in anesthetized, tracheotomised (or orally intubated) and mechanically ventilated subjects. Another limitation of the technique is observable in Figure 5D-5F where data are not available at the highest concentrations for the chlorine-exposed group because the fit of the Constant Phase Model to the data is poor above moderate levels of bronchoconstriction. However, severely bronchoconstricted animals could be assessed by analyzing Zrs directly ${ }^{15}$, or by using third party post-analysis software to fit more complex mathematical models, e.g. taking into account the heterogeneity of mechanical function ${ }^{17}$. Excluded datasets can also be observed if the animal's airways are not sufficiently passive or if the resistance of the cannula is too high. As a rule of thumb, the resistance of the cannula 
should not exceed the animal's resistance at baseline. Working with a cannula of larger inner diameter and/or shorter length will help reduce the cannula resistance. Finally, the present demonstration of FOT measurements in mice may be perceived as a time-consuming and therefore less efficient methodology or less applicable to longitudinal studies compared to less invasive techniques. However the latter are associated with a great deal of uncertainty as to the basis of their outcomes and are viewed by many as being flawed ${ }^{1}$. Repeated invasive measurements are possible in orally intubated animals, although technically more challenging ${ }^{17}$.

From the examples provided, results demonstrated the equivalence of the two generations of the flexiVent system at producing measurements of respiratory mechanics, as well as airway hyperreactivity and hypersensitivity to inhaled methacholine following chlorine-exposure in mice. When used to characterize or understand physiological changes or disease models, the detailed measurement aspect related to the technique can contribute to extend the current state of knowledge.

\section{Disclosures}

AR, LF, TFS are employed by SCIREQ Scientific Respiratory Equipment Inc. TFS also owns stock.

Free access to this article is sponsored by SCIREQ Scientific Respiratory Equipment, Inc.

\section{Acknowledgements}

TKMcG is supported by a studentship from the Canadian Thoracic Society.

\section{AUTHORS' CONTRIBUTION}

All authors took part in the conception of the manuscript. In addition, TKMcG initiated the project, collected experimental results, contributed to the writing of the manuscript and its critical review. AR collected and analyzed experimental results, drafted the manuscript and contributed to its critical review. LF collected experimental results and contributed to the critical review of the manuscript. TFS and JGM contributed to the critical review of the manuscript.

\section{References}

1. Bates, J.H.T. \& Irvin, C.G. Measuring lung function in mice: the phenotyping uncertainty principle. J. Appl. Physiol. 94, 1297-1306 (2003).

2. Bates, J.H.T. Lung mechanics. An inverse modeling approach., Cambridge University Press, New York, (2009).

3. Hantos, Z., Daroczy, B., Suki, B., Nagy, S., \& Fredberg, J.J. Input impedance and peripheral inhomogeneity in dog lungs. J. Appl. Physiol. 72, 168-178 (1992).

4. McGovern, T.K., et al. Dimethylthiourea protects against chlorine induced changes in airway function in a murine model of irritant induced asthma. Respir. Res. 11, 138 (2010).

5. Hayes, R.D., Beach, J.R., Rutherford, D.M., \& Sim, M.R. Stability of methacholine chloride solutions under different storage conditions over a 9 month period. Eur. Respir. J. 11, 946-948 (1998).

6. North, M.L., et al. Augmentation of arginase 1 expression by exposure to air pollution exacerbates the airways hyperresponsiveness in murine models of asthma. Respir. Res. 12, 19 (2011).

7. Siddiqui, S., et al. Site of allergic airway narrowing and the influence of exogenous surfactant in the brown norway rat. PloS ONE. 7, e29381 (2012).

8. Cohen, J.C., Lundblad, L.K.A., Bates, J.H.T., Levitzky, M., \& Larson, J.E. The "Goldilocks Effect" in cystic fibrosis: identification of a lung phenotype in the cftr knockout and heterozygous mouse. BMC Genetics. 5, 21 (2004).

9. Shalaby, K.H., Gold, L.G., Schuessler, T.F., Martin, J.G., \& Robichaud, A. Combined forced oscillation and forced expiration measurements in mice for the assessment of airway hyperresponsiveness. Respir Res, 11, 82 (2010).

10. Thiesse, J., et al. Lung structure phenotype variation in inbred mouse strains revealed through in vivo micro-CT imaging. J. Appl. Physiol. 109, 1960-1968 (2010).

11. Amatullah, H., et al. Comparative cardiopulmonary effects of size-fractionated airborne particulate matter. Inhalation Toxicology. 24, 161-171 (2012).

12. Salazar, E. \& Knowles, J.H. An analysis of pressure-volume characteristics of the lungs. J. Appl. Physiol. 19, 97-104 (1963).

13. Balakrishna, S., et al. Environmentally persistent free radicals induce airway hyperresponsiveness in neonatal rat lungs. Particle Fibre Tox. 8 , $11(2011)$

14. Fahmy, B., et al. In vitro and in vivo assessment of pulmonary risk associated with exposure to combustion generated fine particles. Environ. Toxicol. Pharmacol. 29, 173 (2010).

15. Duguet, A., et al. Bronchial responsiveness among inbred mouse strains. Role of airway smooth-muscle shortening velocity. Am. J. Respir. Crit. Care Med. 161, 839-848 (2000).

16. Bozanich, E.M., et al. Developmental changes in airway and tissue mechanics in mice. J. Appl. Physiol. 99, 108-113 (2005).

17. Schwartz, B.L., et al. Effects of central airway shunting on the mechanical impedance of the mouse lung. Ann. Biomed. Eng. 39, 497-507 (2011).

18. De Vleeschauwer, S.I., et al. Repeated invasive lung function measurements in intubated mice: an approach for longitudinal lung research. Lab Anim. 45, 81-89 (2011)

19. Takubo, Y., et al. a1-Antitrypsin determines the pattern of emphysema and function in tobacco smoke-exposed mice. Am. J. Respir. Crit. Care Med. 166, 1596-1603 (2002).

20. Salerno, F.G., et al. Effect of PEEP on induced constriction is enhanced in decorin-deficient mice. Am. J. Physiol. Lung Cell Mol. Physiol. 293, L1111-L1117 (2007).

21. Therien, A.G., et al. Adenovirus IL-13-induced airway disease in mice. Am. J. Respir. Cell. Mol. Biol. 39, 26-35 (2008). 
22. Bates, J.H.T., Cojocaru, A., \& Lundblad, L.K.A. Bronchodilatory effect of deep inspiration on the dynamics of bronchoconstriction in mice. J. Appl. Physiol. 103, 1696-1705 (2007).

23. Wagers, S.S., et al. Intrinsic and antigen-induced airway hyperresponsiveness are the result of diverse physiological mechanisms. J. Appl. Physiol. 102, 221-230 (2007).

24. Collins, R.A., Sly, P.D., Turner, D.J., Herbert, C., \& Kumar, R.K. Site of inflammation influences site of hyperresponsiveness in experimental asthma. Respir. Physiol. Neurobiol. 139, 51-61 (2003).

25. Bishai, J.M. \& Mitzner, W. Effect of severe calorie restriction on the lung in two strains of mice. Am. J. Physiol. Lung Cell Mol. Physiol. 295, L356-L362 (2008).

26. Song, W., et al. Postexposure administration of $\beta 2$-agonist decreases chlorine-induced airway hyperreactivity in mice. Am. J. Respir. Crit. Care Med. 45, 88-94 (2011).

27. Hirota, J.A., Ellis, R., \& Inman, M.D. Regional differences in the pattern of airway remodeling following chronic allergen exposure in mice. Respir. Res. 7, 120 (2006).

28. Llop-Guevara, A., et al. In vivo-to-in silico iterations to investigate aeroallergen-host interactions. PloS ONE. 3, e2426 (2008). 